This item was submitted to Loughborough's Research Repository by the author.

Items in Figshare are protected by copyright, with all rights reserved, unless otherwise indicated.

\title{
Computer simulation of the King's Cross fire: effect of radiative heat transfer
} on fire spread

\section{PLEASE CITE THE PUBLISHED VERSION}

\section{PUBLISHER}

Professional Engineering Publishing / @ IMechE

VERSION

VoR (Version of Record)

\section{LICENCE}

CC BY-NC-ND 4.0

\section{REPOSITORY RECORD}

Malalasekera, W., and F. Lockwood. 2019. "Computer Simulation of the King's Cross Fire: Effect of Radiative Heat Transfer on Fire Spread". figshare. https://hdl.handle.net/2134/5699. 
This item was submitted to Loughborough's Institutional Repository (https://dspace.lboro.ac.uk/) by the author and is made available under the following Creative Commons Licence conditions.

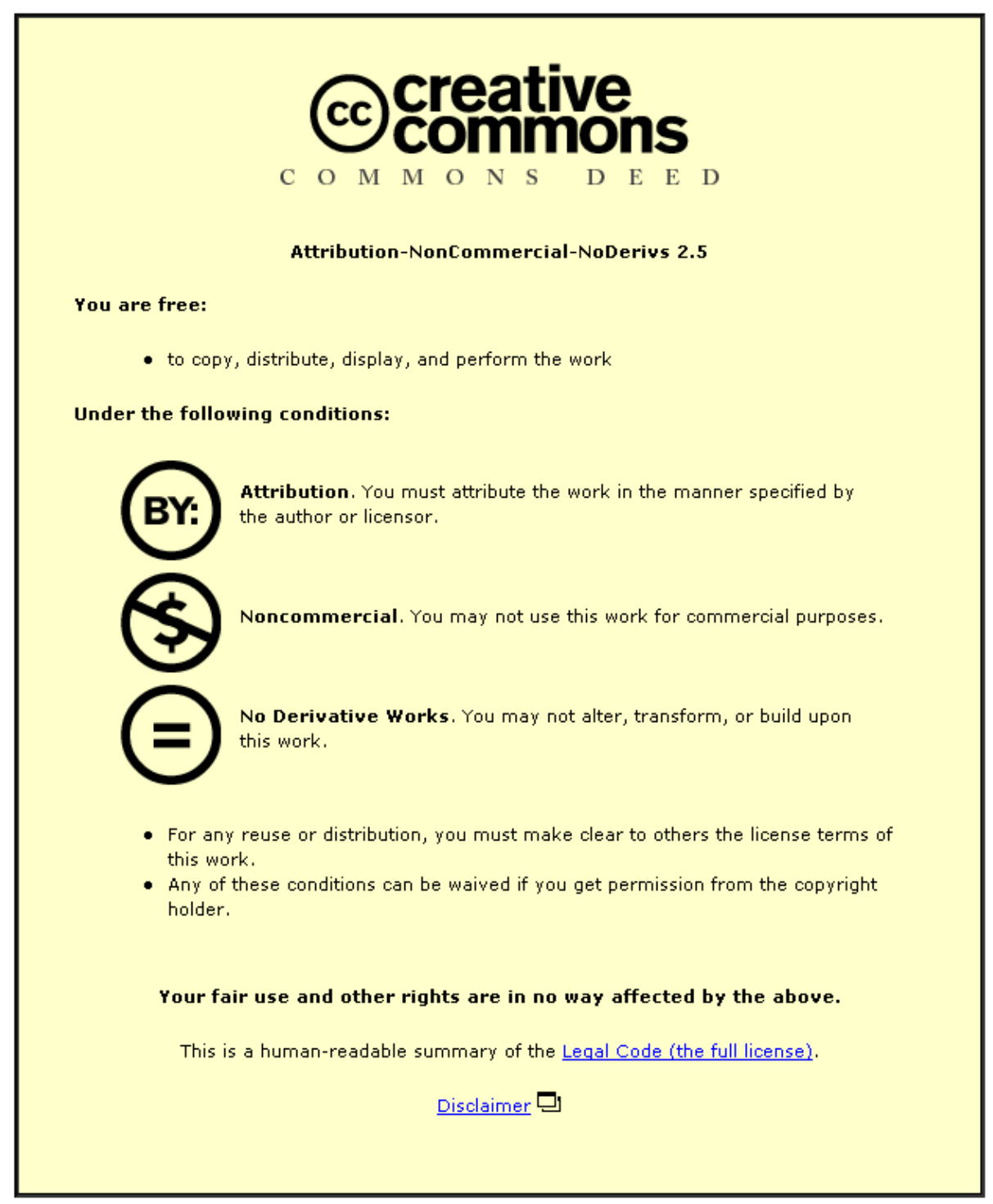

For the full text of this licence, please go to: http://creativecommons.org/licenses/by-nc-nd/2.5/ 


\section{Computer simulation of the King's Cross fire: effect of radiative heat transfer on fire spread}

W M G Malalasekera, BSc, PhD, DIC, MemASME, CEng, MIMechE

Department of Mechanical Engineering, Loughborough University of Technology, Leicestershire

F Lockwood, BSc, PhD, DIC

Department of Mechanical Engineering, Imperial College of Science, Technology and Medicine, London

A mathematical model has been applied to simulate model experiments of the $1987 \mathrm{King}$ 's Cross underground fire by the Department of Health and Safety Executive. The predicted growth of the fire is compared with the experimental data and in particular the predicted and measured times to 'flashover' are compared. The comparisons show exceptional agreement which, in part, may be fortuitous due to the need to facilitate the prediction of the early stages of the growth with the aid of an experimentally estimated fire strength. The good agreement nonetheless is also due to the full description of the radiation transfer which is a feature of the mathematical model. It is concluded that the flashover phenomenon that occurred at King's Cross was thermal radiation driven and that future research should be devoted to modelling the details of fire spread across a combustible surface.

\section{NOTATION}

$a_{\mathrm{g}, i} \quad$ weighting factor for $i$ th band

$E \quad$ blackbody emissive power $=\sigma T^{4}$

$f \quad$ mixture fraction

$g$ gravitational constant

$h$ specific enthalpy

I radiation intensity

$i, j \quad$ tensor designates

$k \quad$ turbulence kinetic energy

$K \quad$ absorption coefficient

$L \quad$ path length

$p \quad$ partial pressure

$P \quad$ pressure

$S \quad$ distance

$S \quad$ source term

$u \quad$ velocity in $x$ direction

$v \quad$ velocity in $y$ direction

$w \quad$ velocity in $z$ direction

$x, y, z$ direction coordinates

\section{Greek symbols}

$\Gamma \quad$ exchange coefficient

$\varepsilon \quad$ turbulence dissipation rate

$\mu \quad$ viscosity

$\rho$ density

$\sigma \quad$ Stefan-Boltzmann constant

$\phi \quad$ dependent variable

$\Omega \quad$ solid angle

\section{Subscripts}

fu fue

g gas

s soot

\section{INTRODUCTION}

A major disaster of the last decade was the King's Cross underground fire which occurred on 18 November 1987.

The MS was received on 11 December 1990 and was accepted for publication on 15 April 1991.
The fire started on the Piccadilly line escalator tunnel and swiftly spread into the ticket hall, killing 31 people and injuring many more (1). It is clear that radiative heat transfer played a major role in spreading the fire towards flashover, subsequent to an initial growth phase. In any enclosed fire, thermal radiation is the most hazardous mode of heat transfer, because it provides a mechanism for the ignition of distant objects and vapour clouds.

King's Cross underground station is one of the most complex of the London underground system. It serves five underground lines and two main lines. On 18 November 1987, a fire started on the Piccadilly line escalator section leading to the ticket hall. The escalator treads were made of wood, the sides were made of plywood backed by mild steel sheets and facia panels were also made of plywood with steel backing. There were solid wood risers, oil-impregnated skirting boards and a large quantity of grease and muck under the escalator. The presence of these wooden sections and combustible material contributed to the fire spread rate, acting as a good fuel source for the developing fire. The details reported in reference (1) after the incident show that almost all the combustible parts were consumed by the fire up to the throat of the ticket hall. Flames emerged from the throat, damaged the ticket hall ceiling and all combustible material found in the ticket hall.

In the investigation, a series of tests to establish the events was carried out by the Department of Health and Safety Executive, UK. These ranged from burning of test samples from the site to full-scale fire growth tests on sections [for details see reference (2)]. Among these tests scale model tests were also conducted to study the sequence of events. The details of these tests can be found in Moodie (2) and Moodie and Jagger (3). For the benefit of that investigation some computer simulations were also carried out by Jones et al. (4) at Harwell Laboratories. In their simulations a CFD technique (field model) was used to study the aerodynamics of the flow caused by the fire and heat transfer in the escalator section. In the simulation, combustion and radiation, which are the most important phenomena in 
fires, were not modelled and the fire was represented by a time-varying source of heat. This paper presents a more comprehensive simulation of the King's Cross fire including combustion and radiative heat transfer. The techniques used here have been developed and tested in a number of previous studies [see, for example, Lockwood and Malalasekera (5), Lockwood et al. (6) and Malalasekera (7)]. In order to validate the present simulation we have chosen the one-third scale tests of the King's Cross fire for simulation of Moodie and Jagger (3). The mathematical method is, of course, equally applicable to full-scale configurations.

In the King's Cross fire, the so-called flashover was a principal reason for the high death total. A strict definition of flashover is not possible, but the term is generally used to describe a relatively sudden and rapid growth of a fire once a critical fire size has been reached. It may be the result of several factors, but the ability of thermal radiation to propagate energy to distant locations is often the root cause. Obviously the ability to predict the time to flashover is much desired since it would enable escape times to be determined.

In previous fire calculations (5), the present authors have shown how radiative transfer may be used to predict approximate flashover times. The same methodology is used in the present simulation to predict flashover times for the one-third model. The quality of these predictions is assessed against the experimental data.

\section{THE MATHEMATICAL MODEL}

The present model is of the 'field model' variety $(5, \mathbf{8}, \mathbf{9})$ and solves the fundamental transport equations for the variables involved. It predicts the development of the fields of flow, temperature, heat transfer, smoke and species concentrations such as carbon dioxide. In predicting compartment fires the origin of the fire, the configuration with appropriate boundary conditions and the source of the fire are the inputs.

The simulation of the aerodynamics and combustion is embodied in the solution of balance equations for velocities $u, v$ and $w$ in the three coordinate directions $x$, $y$ and $z$ respectively; the enthalpy $h$; the mixture fraction $f$; the turbulent kinetic energy $k$; and its dissipation rate $\varepsilon$. The equations have a common form which in Cartesian tensor notation may be expressed as

$$
\frac{\partial}{\partial t}(\rho \phi)+\frac{\partial}{\partial x_{j}}\left(\rho u_{j} \phi\right)=\frac{\partial}{\partial x_{i}}\left(\Gamma \frac{\partial \phi}{\partial x_{j}}\right)+S_{\phi}
$$

where $\phi$ stands for any one of the above-mentioned variables and $S_{\phi}$ is the source term.

The thermal radiation is governed by the fundamental transfer equation:

$$
\frac{\mathrm{d} I}{\mathrm{~d} s}=-K I+\frac{K \sigma T^{4}}{\pi}
$$

where $I$ is the radiation intensity in the direction of $s, K$ is the absorption coefficient, $\sigma$ is the Stefan-Boltzmann constant and $T$ is the temperature. As smoke particles are generally small enough for scattering to be negligible, both the in-scattering and out-scattering terms have been neglected in this equation.

\section{NUMERICAL SOLUTION TECHNIQUE}

\subsection{Combustion and aerodynamics}

The solution technique employed to solve equation (1) has been fully described on numerous occasions [see, for example, references (10) and (11)] and only an outline is required here. The compartment is subdivided into a number of 'cells' or 'control volumes' formed by the placement of a computational grid. The differential equations are replaced by approximate finite difference equations obtained by integration over a cell volume. The differential equations form a set of algebraic equations which are then solved by standard matrix solution algorithms. A Poisson-form pressure correction equation, deduced from the mass continuity equation, is used to correct the velocity values to satisfy mass continuity. This standard solution technique, often summarized by the acronym SIMPLE, is fully described in reference $(\mathbf{1 0})$.

\subsection{Radiation heat transfer}

The discrete transfer (DT) method of Lockwood and Shah (12) is used here to solve the radiation transfer equation (2). This procedure is numerically exact and applicable to arbitrarily shaped geometrical configurations and is rapidly becoming popular in various numerical combustion prediction applications. The intensity $I$ along a discretized direction $\Omega$ is very rapidly determined with the aid of the recurrence relation obtained after integrating equation (2):

$$
I_{n+1}=I_{n} \exp (-K \delta s)+E_{n}\{1-\exp (-K \delta s)\}
$$

where $E=K \sigma T^{4} / \pi$ and the subscripts $n$ and $n+1$ designate successive locations along $\Omega$ separated by the incremental distance, $\delta s$.

Equation (3) is applied to discretized solid angle elements within which the intensity value is presumed uniform. When a sufficient number of solid angle elements are employed the DT method is exact, economical and applicable to arbitrary geometrical shapes. It is fully described in reference (12).

In this study a user friendly computer code known as CINAR (6) (an acronym for combustion integrated, numerical algorithm with radiation) has been used. The user is able to represent the geometry using a simple coding system, and user modification of the source code is unnecessary. The geometrical representation system used in CINAR allows the user to model easily complex geometrical configurations such as the escalator tunnel of the present study. The radiation routine incorporated in CINAR allows the calculation of the radiative transfer at arbitrary placed surface elements. More details about this code and about its use can be found in references (6) and (13).

\section{FURTHER MODELLING EFFORTS REQUIRED FOR FIRE SIMULATIONS}

\subsection{Modifications to standard $\boldsymbol{k}-\boldsymbol{\varepsilon}$ model}

The fluid motion in fires in enclosures is dominated by mean buoyancy effects. It has been found, as did Cox et al. (14), that the standard $k-\varepsilon$ turbulence model requires modifications for the satisfactory prediction of the fluid 
flow in these circumstances. A buoyancy production term, $G_{\mathbf{B}}$, recommended by Rodi (15), is appended to the source term for the $k$ equation:

$$
G_{\mathrm{B}}=-\beta g \frac{\mu_{\mathrm{t}}}{\sigma_{k}} \frac{\partial T}{\partial z}
$$

The corresponding modification to the source term $S_{\varepsilon}$ of the $\varepsilon$ equation is also used, which is

$$
S_{\varepsilon}=C_{1} \frac{\varepsilon}{k}\left(G_{k}+G_{\mathrm{B}}\right)\left(1+C_{3} R_{3}\right)-C_{2} \rho \frac{\varepsilon^{2}}{k}
$$

Here $G_{k}$ is the standard shear production term in the $k$ equation, $C_{3}$ is a model constant, $R_{3}$ is the Richardson number and $C_{1}$ and $C_{2}$ are standard model constants in the $\varepsilon$ equation.

\subsection{The thermal radiation properties}

In fires, the large quantities of soot produced during combustion of typical materials significantly augments the absorption coefficient of radiative transfer. A reasonable estimate of the soot concentration is important to the calculation of the correct radiation transfer. A balance equation for the soot in the form of equation (1) is solved with $\phi$ standing for the soot mass fraction, $m_{\mathrm{s}}$. Source terms $S_{\mathrm{f}}$ and $S_{\mathrm{c}}$ appear in this equation representing, respectively, the soot formation and consumption rates.

The simulation of soot production has to a large extent defied modelling efforts. The simple kinetic expression reported in reference (16) is used here:

$$
S_{\mathrm{f}}=C_{\mathrm{f}} p_{\mathrm{fu}} \phi^{n} \exp \left(\frac{-E_{\mathrm{f}}}{R T}\right)
$$

where $C_{\mathrm{f}}$ is a constant which depends on the fuel type and the Richardson number, $p_{\mathrm{fu}}$ is the fuel partial pressure, $\phi$ is the local equivalence ratio, $n$ is a model constant, $E$ is the activation energy and $R$ is the universal gas constant. This expression allows for all the known factors influencing soot production. The soot burnout rate may be influenced by both chemical kinetics and the turbulence decay rate. The chemical kinetic consumption rate is obtained by the Lee et al. (17) expression:

$$
S_{\mathrm{b}, \mathrm{k}}=C_{\mathrm{d}} m_{\mathrm{s}}\left(\frac{p_{\mathrm{O} 2}}{\sqrt{ } T}\right) \exp \left(-\frac{E}{R T}\right)
$$

where $p_{\mathrm{O} 2}$ is the partial pressure of $\mathrm{O}_{2}, C_{\mathrm{d}}$ is a model constant given the value 3.6 and $E / R$ is taken as 20000 which are the values specified by Abbas and Lockwood (16). The turbulence decay rate is obtained from the expression of Magnussion and Hjertager (18):

$$
S_{\mathrm{b}, \mathrm{t}}=\min \left\{A m_{\mathrm{s}} \frac{\varepsilon}{k}, A \frac{m_{\mathrm{O}_{2}}}{r_{\mathrm{fu}}}\left(\frac{m_{\mathrm{s}} r_{\mathrm{s}}}{m_{\mathrm{s}} r_{\mathrm{s}}+m_{\mathrm{fu}} r_{\mathrm{fu}}}\right) \frac{\varepsilon}{k}\right\}
$$

where $m_{\mathrm{fu}}, m_{\mathrm{O}_{2}}$ are fuel and $\mathrm{O}_{2}$ mass fraction and $r_{\mathrm{fu}}$ and $r_{\mathrm{s}}$ are stochiometric ratios for fuel and soot. $A$ is given a value of 4.0. $S_{\mathrm{b}, \mathrm{k}}$ and $S_{\mathrm{b}, \mathrm{t}}$ are both calculated and the lesser of the two is used as $S_{\mathrm{c}}$.

The gaseous products of combustion are highly nongrey. In many predictions of furnace radiation heat transfer a pseudo-grey treatment based on the 'mixed grey gases' concept of Hottel (19) has been found to work very well $(13,20)$. This approach, as modified by Truelove (21), is retained here:

$$
\varepsilon_{\mathrm{g}}=\sum_{i=0}^{n} a_{\mathrm{g}, i}\left[1-\exp \left(-K_{\mathrm{g}, i} P_{\mathrm{g}, i}-K_{\mathrm{s}, i} C\right) L\right]
$$

where $P_{\mathrm{g}, i}$ is the partial pressure of an absorbing and participating gas (here $i=$ fuel, $\mathrm{H}_{2} \mathrm{O}$ or $\mathrm{CO}_{2}$ ), $K_{\mathrm{g}, i}$ is the absorption coefficient of the gas $i, K_{\mathrm{s}, i}$ is the volumetric soot absorption coefficient, $C$ is the soot concentration per unit volume and $L$ is the mean radiation path length which is here set equal to the discretized distance $\delta s$ in each application of the recurrence relation (3). The coefficients $a_{\mathrm{g}, i}, K_{\mathrm{g}, i}$ and $K_{\mathrm{s}, i}$ are those specified by Truelove. The pseudo-grey absorption coefficient $K$ for use in recurrence relation (3) is extracted from

$$
\varepsilon=1-\exp (-K \delta s)
$$

\section{APPLICATION OF THE MODEL TO KING'S CROSS FIRE, ONE-THIRD MODEL EXPERIMENTS}

In the Health and Safety Executive Department experiments (3), the escalator shaft was constructed of galvanized sheets and provided a tunnel with inclination $30^{\circ}$ which was very similar to the actual King's Cross geometry. The escalator section had wooden steps and led to the constructed booking hall in the same manner as for the full-scale arrangement (Figs 1 and 2). At the end of the booking hall (looking from the escalator end) an exhaust duct was placed to remove combustion products from the model. The whole setup was thoroughly instrumented with thermocouples and video recording equipment as shown in Figs 1 and 2. Species concentration measurements were carried out at the exhaust duct and heat flux measurements were recorded at several booking hall locations, indicated in the figures.

Several tests were carried out using different ignition sources, such as standard wood cribes, and applied grease layers. The test considered in this simulation used lithium grease as the ignition source. In this test the fire was initiated on the step $7.46 \mathrm{~m}$ from the top of the escalator section (see Fig. 1).

Initial predictions were attempted for the combined escalator plus booking hall using a complex grid of $60 \times 26 \times 45$. However, in-house computing restrictions which prevailed at the time forced consideration of only the escalator portion of this geometry using a reduced grid of $37 \times 14 \times 43$. Figure 3 shows this grid in an $x-z$ plane. In formulating the grid in the $x-y$ plane, care was given to represent all geometrical details of the tunnel section. To represent the tunnel crosssection in the $x-y$ plane 132 grid cells were used and the number of grid cells used in the calculation, excluding the cells that lie outside the domain, were $132 \times 37$.

The rate of fire spread depends on many factors: material properties, radiative and convective heat transfer to the flammable surface from the fire, conduction heat transfer within the surface material, the material pyrolysis chemistry, the composition of the pyrolysis gases, the chemical kinetics of the postpyrolysis surface material and the availability of oxygen in the vicinity of the surface. No attempt has been made to simulate the details of ignition and the immediate postignition flame 


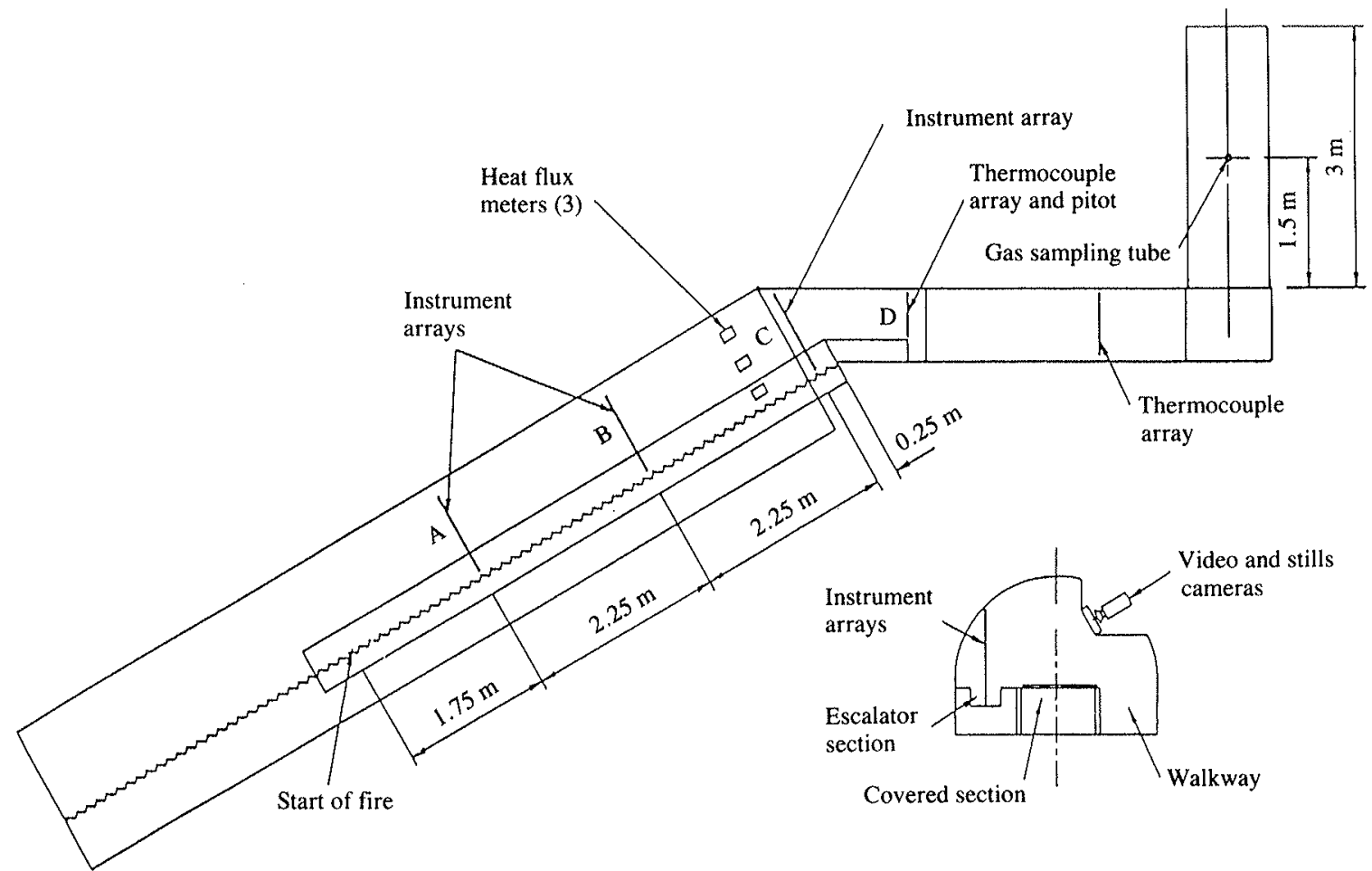

Fig. 1 Elevation of the one-third scale model

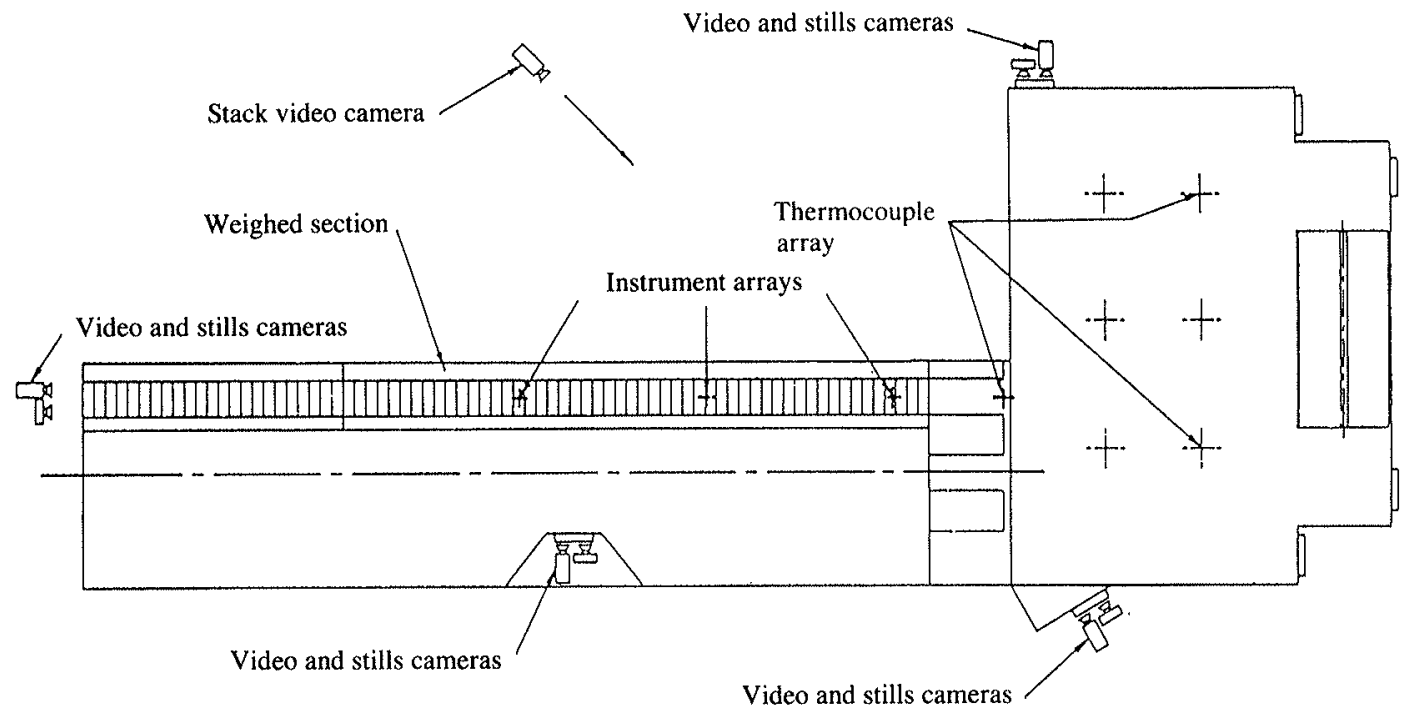

Fig. 2 Plan of the one-third scale model

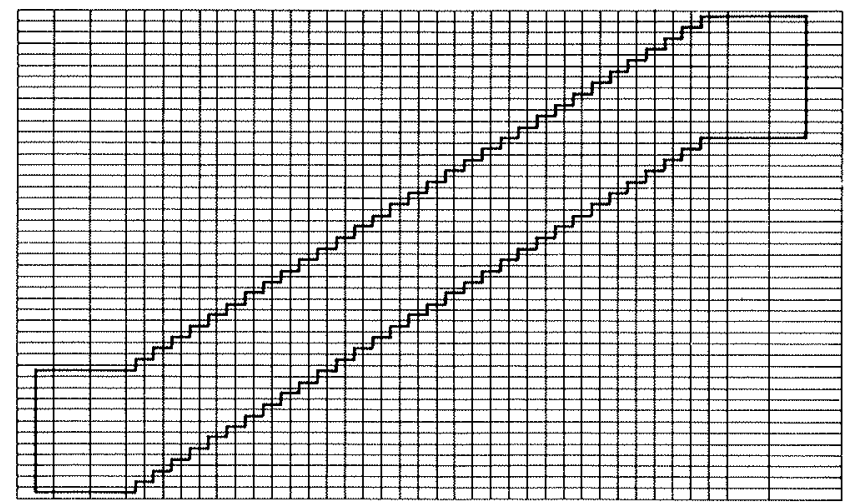

Fig. $3 x-z$ calculation grid used for the simulation of fire in the escalator section spread of the experiments. Instead, an initial fire strength of $100 \mathrm{~kW}$ was assumed, a magnitude consistent with the ignition source of the experiments, located in accordance with the experiments $7.46 \mathrm{~m}$ from the top of the escalator (see Fig. 1).

The dominant mode of heat transfer from the fire to a surface is thermal radiation. This was determined at $50 \mathrm{~s}$ time intervals and the fire was assumed to advance at the same rate as the incident flux contour of 80 $\mathrm{kW} / \mathrm{m}^{2}$. This value is somewhat higher than the usual critical net heat flux for wood of $20-30 \mathrm{~kW} / \mathrm{m}^{2}$ since in the absence of detailed boundary calculations, the surface temperature, required to determine the net heat flux from the incident value, is unknown; nor was it measured in the experiments. 


\section{SIMULATION RESULTS AND COMPARISONS}

Figure $4 a$ to $f$ shows the development with time of the radiative heat transfer to the escalator steps. The contours exhibit expected forms and are biased in the direction of the booking hall due to natural convection. After about $500 \mathrm{~s}$ a much more rapid increase in fire growth is indicated. It is logical to associate this much increased fire growth rate with the flashover phenomenon. The simulation suggests a time to flashover of about $550-575 \mathrm{~s}$.

The observations are confirmed by the prediction of fire length (actual burn length normalized by the width of the section) shown in Fig. 5. The experimental estimates of the fire length are also shown in this figure.

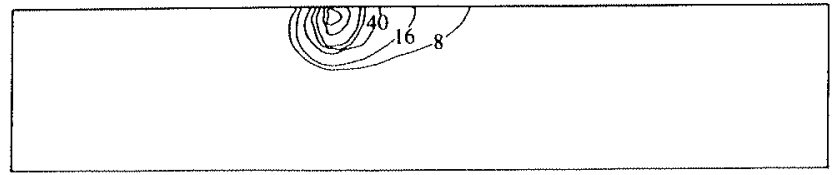

(a) At 100 s from ignition

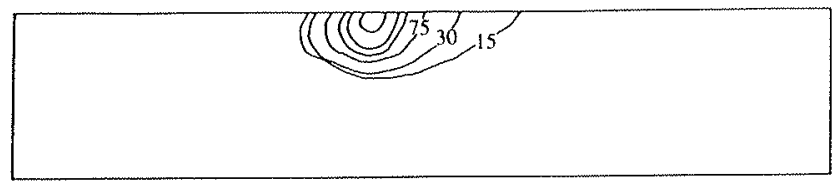

(b) At $200 \mathrm{~s}$ from ignition

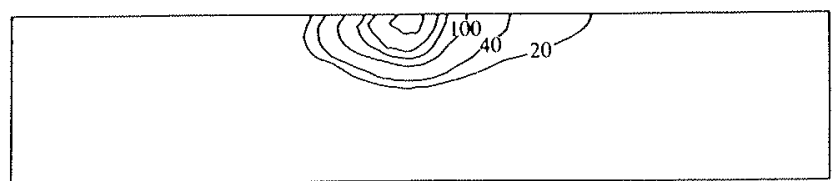

(c) At $300 \mathrm{~s}$ from ignition
The predictions and the data display similar behaviour but the experiments show a sharper onset of flashover. It is barely worth discussing possible reasons for the discrepancies since the assumptions of the simulations have bridged many details, but there is no doubt associated with the specific manner in which the volatiles were released from the escalator material when subjected to the heat of the fire.

Figure 6 shows the development with time of the temperature field in the escalator passage. Again there is nothing unexpected about the behaviour of the contours. They confirm an increase of fire growth rate commencing some $500 \mathrm{~s}$ after ignition with the arrival of destructively elevated temperatures in the ticket hall at about $550 \mathrm{~s}$. Figures 7 and 8 show comparisons of the

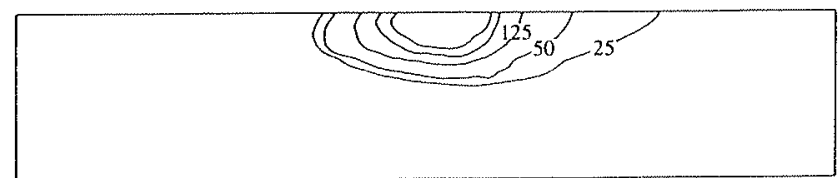

(d) At $400 \mathrm{~s}$ from ignition

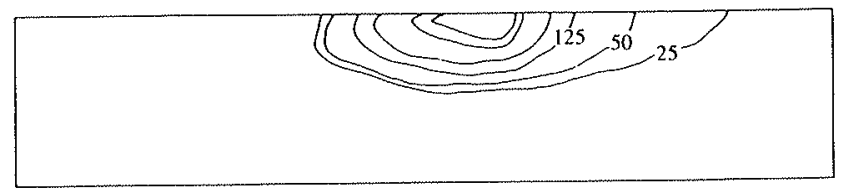

(e) At $500 \mathrm{~s}$ from ignition

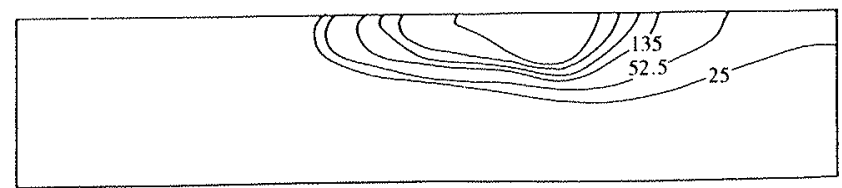

(f) At $550 \mathrm{~s}$ from ignition

Fig. 4 Transient development of radiative heat transfer $\left(\mathrm{kW} / \mathrm{m}^{2}\right)$ to the escalator steps

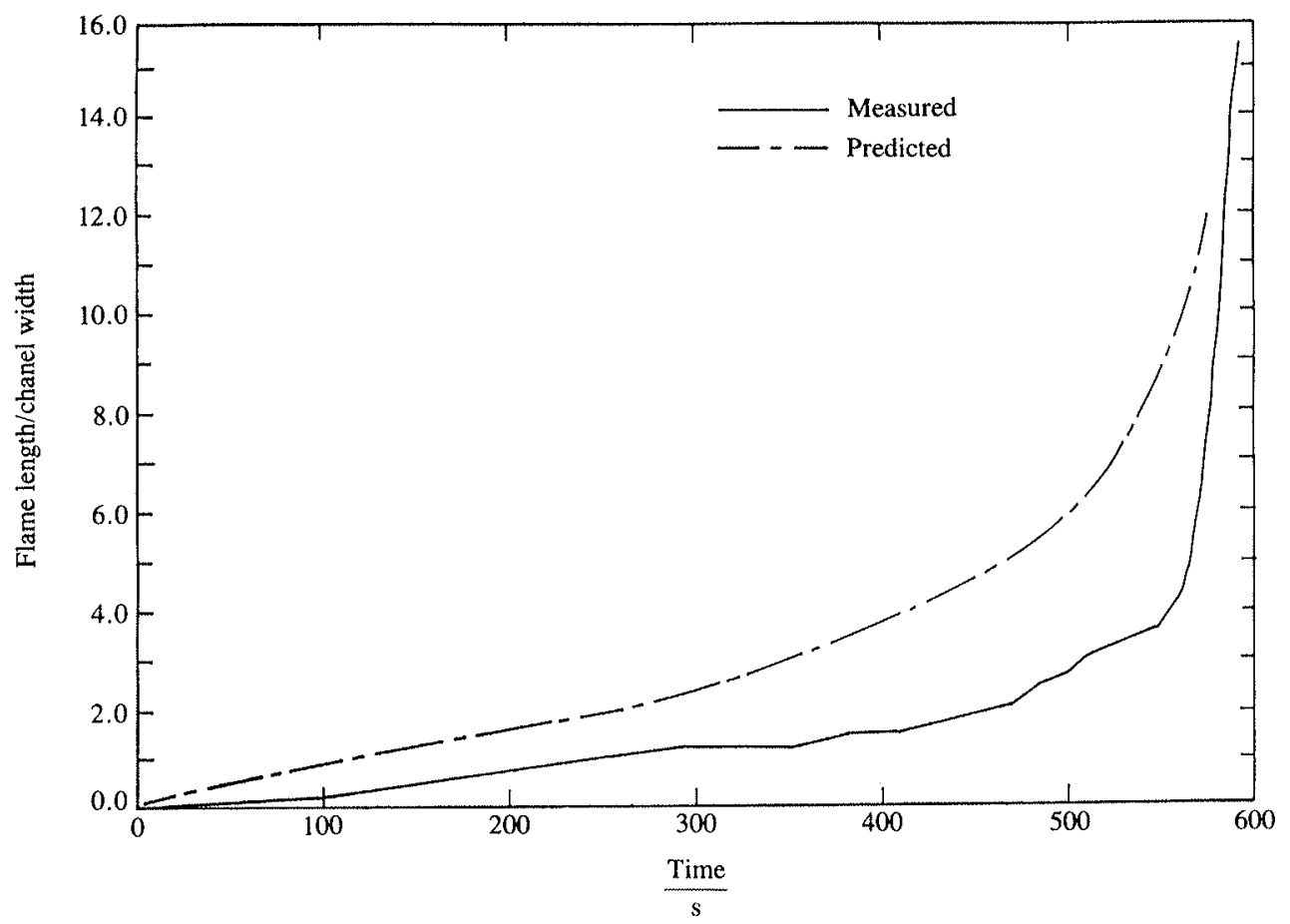

Fig. 5 Comparison of predicted and measured fire length 


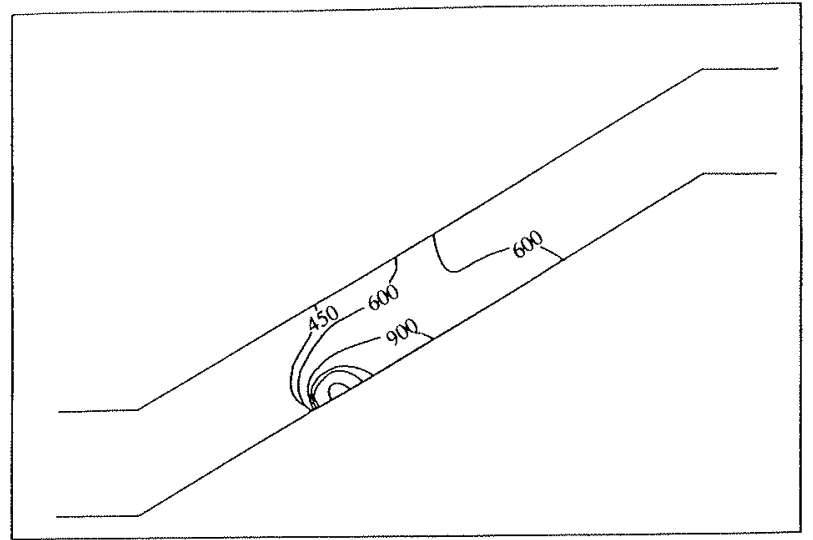

(a) At $100 \mathrm{~s}$ from ignition

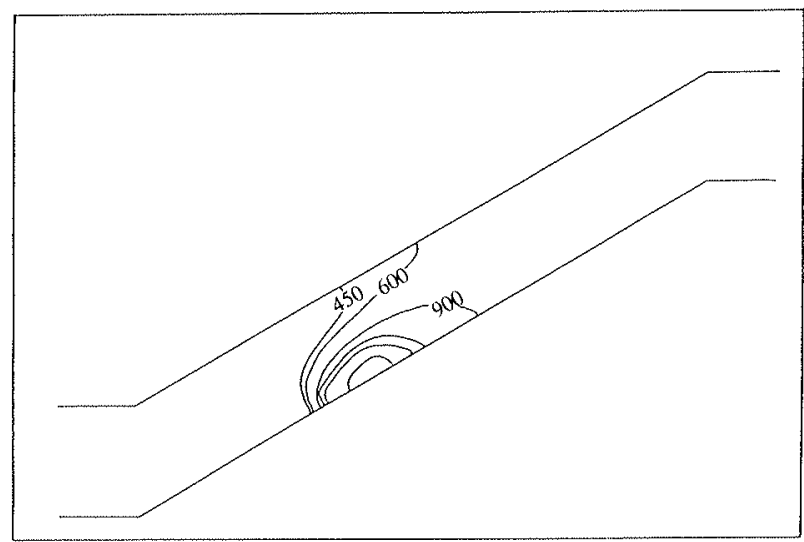

(b) At $200 \mathrm{~s}$ from ignition

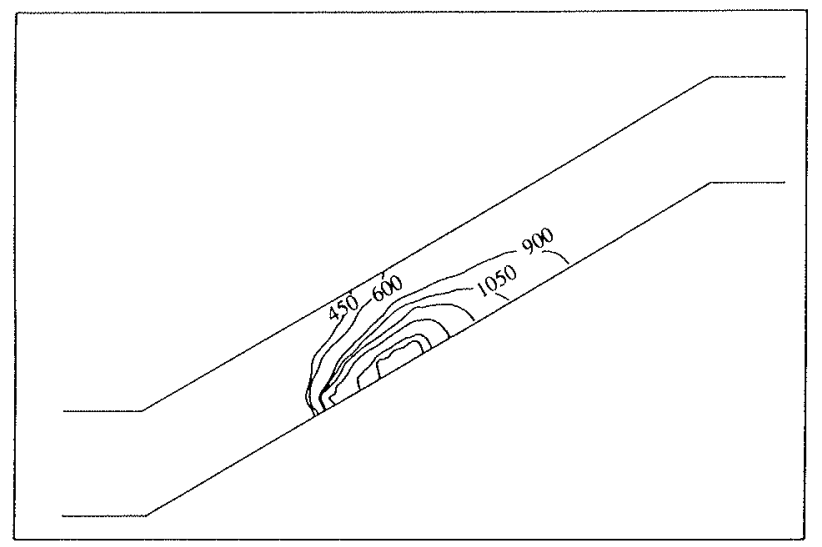

(c) At $300 \mathrm{~s}$ from ignition

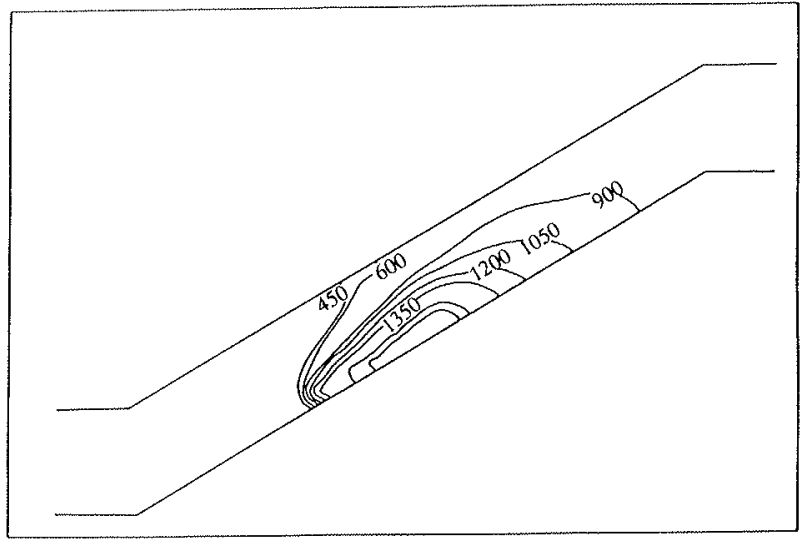

(d) At $400 \mathrm{~s}$ from ignition

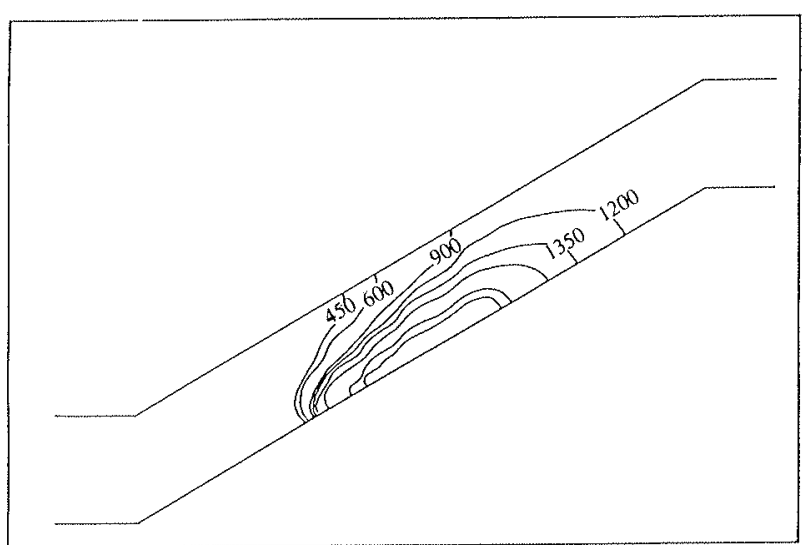

(e) At $500 \mathrm{~s}$ from ignition

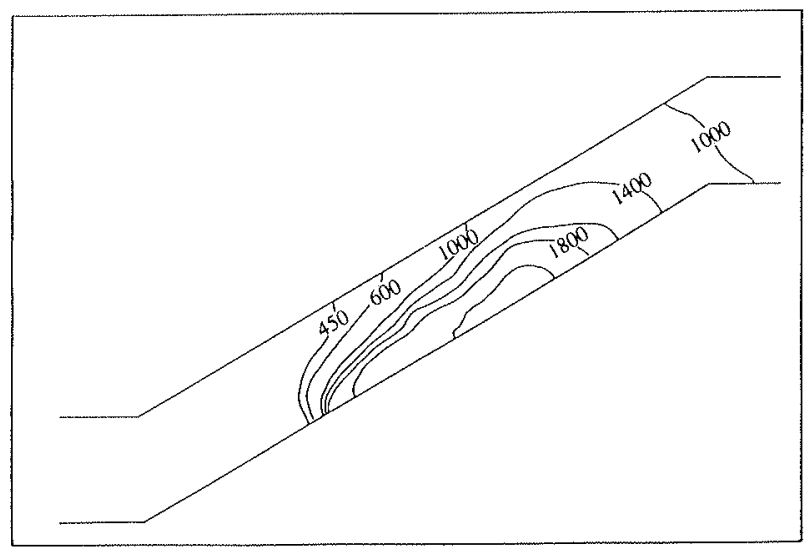

(f) At $550 \mathrm{~s}$ from ignition

Fig. 6 Transient development of temperature (K) inside the escalator tunnel (plane $J=3$ )

predicted and measured temperature variations with time at two stations, A and B, as indicated in Fig. 1. The temperature data, which were obtained with these thermocouples, may be expected to possess greater accuracy than those for flame length which is always difficult to define in the extensively fluctuating conditions of a buoyancy-driven turbulent flow. The agreement between the predictions and the measurements is quite remarkable.

\section{CONCLUSIONS}

In the model experiments the initial fire spread in the escalator portion occurred over a period of $570 \mathrm{~s}$. A further $37 \mathrm{~s}$, which may be viewed as the flashover period, brought the flames into the booking hall, giving an 'escape time' for the people in that vicinity of some $607 \mathrm{~s}$. From the results of the simulation an escape time of 550-575 s has been estimated. Of course, this exceptional agreement is to some extent fortuitous in that estimates of the strength of the initial fire source $(100$ $\mathrm{kW})$ and of the critical flux for ignition $\left(80 \mathrm{~kW} / \mathrm{m}^{2}\right)$ seem to have been good ones. It is important to note here that the calculation process included full convective effects that were relatively important, but calculated convective heat fluxes were not used in the criteria for determining flame spread because the surface temperatures were unknown and heat transfer into the escalator surface by conduction was not accounted for in this simulation. 


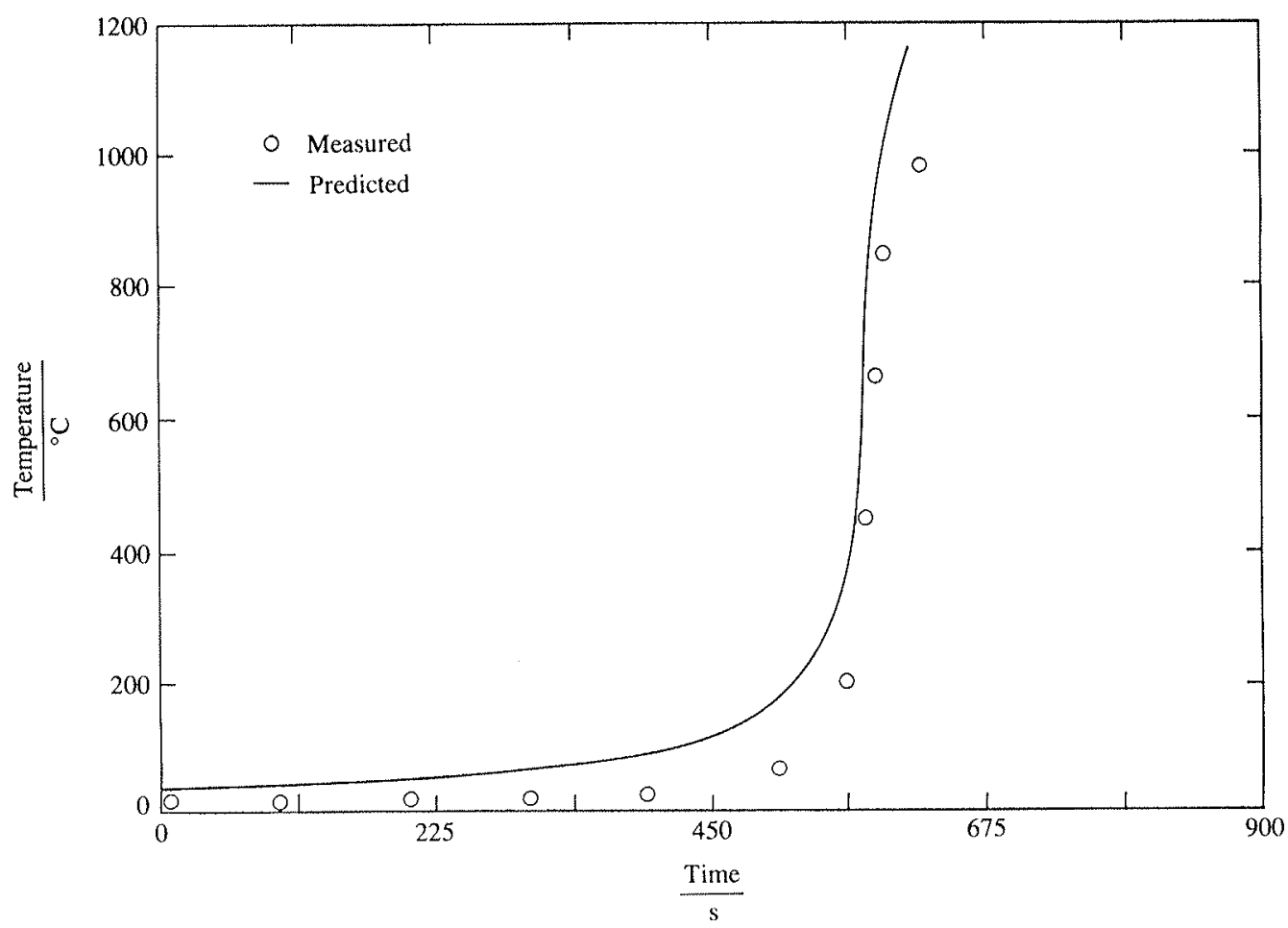

Fig. 7 Comparison of predicted and measured temperature profiles at station A shown in Fig. 1

The much preferred approach would be to introduce into the code a detailed computation of the conditions near and within the combustible surface. As already indicated this is a major computational task, with expensive fine grids being required in the said region and the necessity of introducing complex physical modelling for processes such as the release of volatile substances and burnout of the residual char. Since the initial growth of a fire is very frequently slow no method professing to simulate the time to flashover can be called complete if the details of the fire spread along the combustible surface are not addressed.

Some important conclusions can be drawn from this study. The predicted temperature contours illustrate the formation of the buoyant plume along the escalator. This is known as the 'trench effect'. In this geometrical configuration the formation of this layer of gases increases the radiation feedback to the escalator surface.

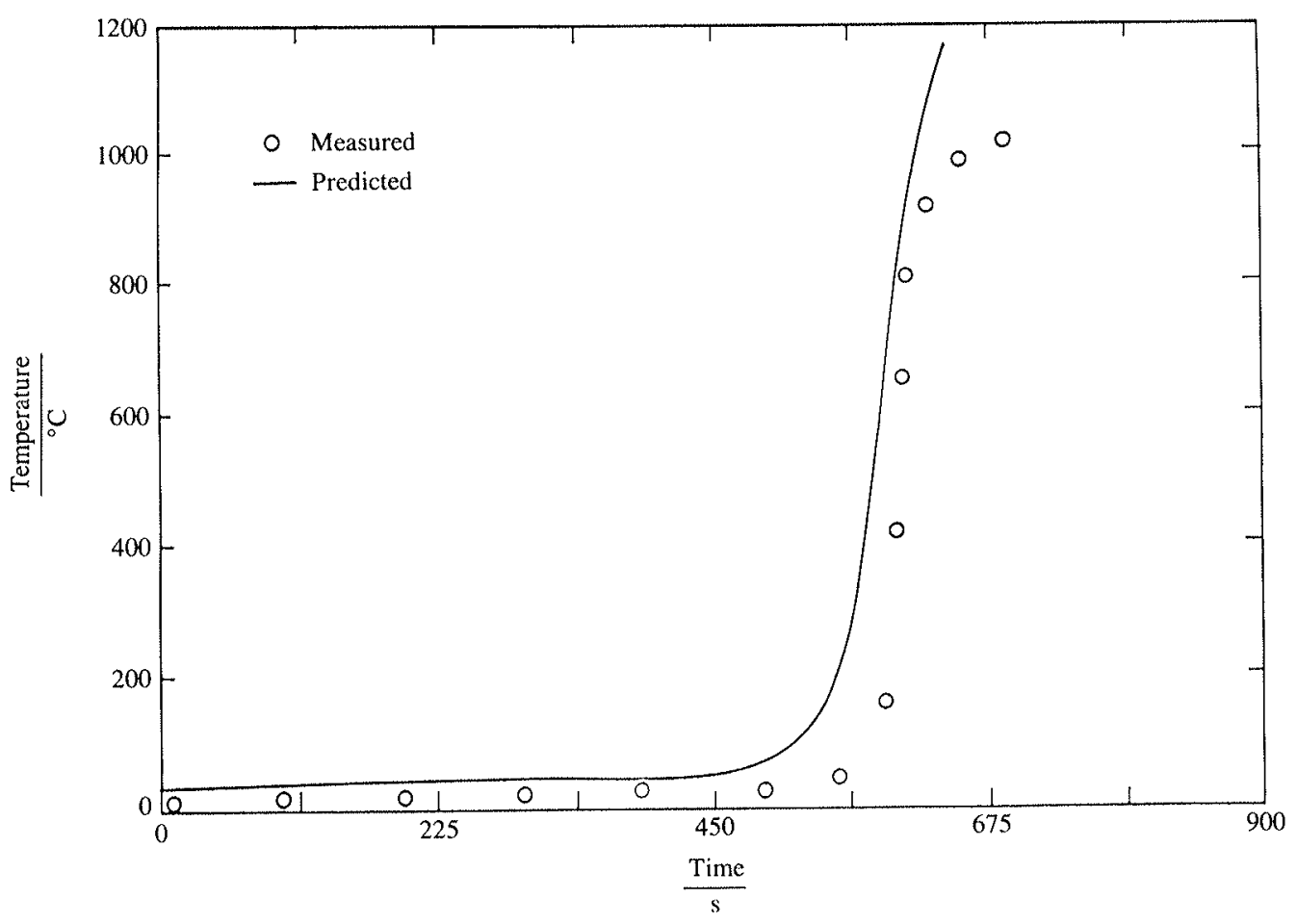

Fig. 8 Comparison of predicted and measured temperature profiles at station B shown in Fig. 1 
However many complex processes can be identified in the King's Cross fire, and among these ought to be included the forced convection created by the continuing movement of trains (a likely significant factor that has not so far been mentioned), the primary causes of the flashover phenomenon that occurred at King's Cross with such devasting effect were a combination of the 'trench effect' and thermal radiation. There is no possibility that the model experiments, which appear themselves to have been a close replication of the real fire, could have been simulated to the degree shown without having included in the present mathematical model a proper description of the radiation process. It is likely that the conclusions may be applied to the majority of fires.

\section{ACKNOWLEDGEMENTS}

The authors wish to thank the United Kingdom Home Office for the financial support for this study and for also providing video recordings and experimental data from the Department of Health and Safety Executive. They particularly wish to thank Geoff Cox, of Fire Research Station, UK, for much helpful technical advice.

\section{REFERENCES}

1 Fennell, D. Investigation into the King's Cross underground fire, Command paper CM499, 1988, Department of Transport (HMSO, London).

2 Moodie, K. Damage assessment and overview of the technical investigation. IMechE Seminar on The King's Cross underground fire: fire dynamics and the organization of safety, July 1989, p. 7 (Mechanical Engineering Publiçations, London).

3 Moodie, K. and Jagger, S. F. Results and analysis from the scale model tests. IMechE Seminar on The King's Cross underground fire: fire dynamics and the organization of safety, July 1989, pp. 27-40 (Mechanical Engineering Publications, London).

4 Jones, I. P., Simcox, S. and Wilkes, N. S. Computer simulation of the flows of hot gases from fire at King's Cross underground station. IMechE Seminar on The King's Cross underground fire: fire dynamics and the organization of safety, July 1989, pp. 19-26 (Mechanical Engineering Publications, London).

5 Lockwood, F. C. and Malalasekera W. M. G. Fire computation: the flashover phenomenon. Twenty-Second Symposium (International) on Combustion, 1988, p. 1319 (The Combustion Institute).

6 Lockwood, F. C., Malalasekera, W. M. G. and Papadopoulos, C. Experience with the CINAR code for three dimensional furnace predictions. Conference on British Flame Days, September 1988, (Institute of Energy)

7 Malalasekera, W. M. G. Mathematical modelling of fires and related processes. PhD thesis, 1988, University of London.

8 Cox, G., Kumar, S., Markatos, N. C. Some field model validation studies. Proceedings of the First International Symposium on Fire safety science, 1986, p. 159 (Hemisphere, Washington DC).

9 Cox, G., and Kumar, S. Field modelling of forced ventilated enclosure fires. Combust. Sci. Technol., 1986, 52, 7.

10 Patankar, S. V. Numerical heat transfer and fluid flow, 1980, (Hemisphere, Washington DC).

11 Lockwood, F. C. The modelling of turbulent premixed and diffusion combustion in the computation of engineering flows. Combust. and Flame, 1977, 29, 111.

12 Lockwood, F. C. and Shah, N. G. A new radiation method for incorporation in general combustion prediction procedures. Eighteenth Symposium (International) on Combustion, 1981, p. 1405 (Combustion Institute).

13 Lockwood, F. C., Malalasekera, W. M. G. and Papadopoulos, C. Steel and glass furnace modelling. Conference on Applied energy, Swansea, 1989, p. 341 (Institute of Energy).

14 Cox, G., Markatos, N. C. and Malin, M. K. Mathematical modelling of buoyancy induced smoke flow in enclosures. J. Heat and Mass Transfer, 1982, 25(1), 63.

15 Rodi, W. Turbulence models and their applications in hydraulics, 1980 (International Association for Hydraulic Research, Delft, Netherlands).

16 Abbas, A. S. and Lockwood, F. C. A note on the prediction of soot concentrations in turbulent diffusion fiames. $J$. Energy, September $1985,112$.

17 Lee, K. B., Thring, M. W. and Beèr, J. M. On the rate of combustion of soot in a laminar soot flame. Combust. and Flame, 1962, $6,137$.

18 Magnussion, B. F. and Hjertager, B. H. On the mathematical modelling of turbulent combustion with special emphasis on soot formation. Sixteenth Symposium (International) on Combustion, 1976 , p. 719 (Combustion Institute).

19 Hottel, H. C. and Sarofim, A. F. Radiative transfer, 1967 (McGraw-Hill, New York).

20 Abbas, A. S., Lockwood, F. C. and Salooja, A. P. The prediction of the combustion and heat transfer performance of a refinery heater. Combust. and Flame, 1984, 58, 91.

21 Truelove, J. Mixed grey gas model for flame radiation. UK AERE Harwell report HL76/3448, 1976. 